\title{
Modernization of reclamation agriculture management systems
}

\author{
Irina Yurchenko ${ }^{1}$, Mikhail Bandurin ${ }^{2, *}$, and Inna Bandurina $^{2}$ \\ ${ }^{1}$ All-Russia Research Institute of Hydraulic Engineering and Reclamation named after A.N. Kostyakov, 44, Bolshaya Akademicheskaya \\ st. Moscow, 127550, Russia \\ ${ }^{2}$ Kuban State Agrarian University named after I.T. Trubilin, 13, Kalinina st., Krasnodar, 350044, Russia
}

\begin{abstract}
Today, a brand new strategy that can foster agricultural production is being shaped based on IT solutions. The paper characterizes the state and prospects for the development of digital farm management, the challenges of mastering digital innovations by agricultural enterprises and ways to tackle them at the present stage. A study is relevant due to the lack of a conceptual approach to the evolution of information digital systems in the sector of ameliorative economy in the context of growing requirements for environmental safety and competitiveness of agricultural production. The solutions to create a common information environment uniting an enterprise with suppliers of resources and consumers of products (services) are also increasingly relevant today. A methodological toolkit rests on some general scientific approaches, including analysis and synthesis, methods of deduction and systems analysis, cluster approach. After careful evaluation of automated processes at reclamation enterprises, there can be no doubt that it is necessary to improve the efficiency of information and technological support for management decisions by digital systems. The challenges are related to: lack of proper concept and methodology of modern digital systems, as well as procedures for the integration cooperation of information resources and a digital management system operations for managing them; unified algorithms for handling information; automation operations that meet the present management requirements; qualified experts encouraged to improve the use of digital technologies. The basic procedures for enhancing digital systems at enterprises include: analytical evaluation of current production situation, development of a functional design and model of the integrated digital system; creation of a mechanism for its implementation. In the process of transforming digital support for managerial actions, the following actions are possible: modification of the structure of existing processes; automation of conventional technological and organizational production procedures; alignment of existing processes subject to the technologies being integrated; identification of new opportunities for operations.
\end{abstract}

\section{Introduction}

The need for permanent improvement of information support for management decisions in the reclamation sector is due to a severe man-made effect it has on the properties of the most important natural components (soil fertility, water quality in water bodies, etc.) and a subsequent heavy price paid for incorrect decisions.

Besides this, water reclamation enterprises are characterized by low implementation, utilization and update of information technologies for management as compared by successful enterprises of domestic economy and foreign countries, which is fraught with less reliable assessments of the ecological and economic efficiency of reclamation activities and the competitiveness of the enterprise [1].

The paper aims to work out recommendations for digital development of reclamation water enterprises with a priority digital support [2] of product life cycle management.

The problem is addressed due to the lack of a conceptual approach to the evolution of information digital systems at organizations in the sector of land reclamation in the face of increasing requirements for environmental safety and competitiveness of agricultural production through the integration cooperation between organization management and functional subdivisions [3]. At present, to promote the development of the amelioration sphere, given the technological diversity of agricultural production, it is becoming more promising to establish integration structures being reclamation clusters in the regional farming sector. Moreover, it is increasingly relevant to come up with the solutions towards a single information space uniting an enterprise with resource suppliers and consumers of products (services) [4].

\section{Materials and methods}

A methodological basis is made up of general scientific approaches, including analysis and synthesis, methods of deduction and systems analysis, cluster approach. Global and national experience in strengthening agricultural

\footnotetext{
*Corresponding author: chepura@mail.ru
} 
production is directly related to information technologies, but in Russia this area is not given due consideration and is still "in the making" [5].

An example of successful implementation of information resources in the agrarian sector is the Food and Agriculture Organization of the United Nations. Since 1945, the latter has been engaged in global food security and agricultural development based on the necessary and reliable information, which contributes to making effective decisions and identifying the risks of environmental and economic decisions associated with the utilization of certain technologies [6].

Today, a Russian farmer finds it most intractable to obtain reliable information that encourage proper managerial and control actions timely and in due amount. Effective management of agricultural production is hampered by such problems as the lack of information about the region of agricultural production, the nature of land tenure and the lack of updated cartographic materials.

The digital economy in Russia is reported to rest on effective infrastructure that creates enabling conditions for the innovative development of production; ensures the performance of "smart" enterprises, environmental security, cyber protection of the virtual space and a corporate equilibrium of business; include communication hardware, computer networks, data processing centers and a system of virtual organizations; provide new digital services to the state, business and citizens in reliable communications, computing power, information systems, services, digital platforms through domestic technologies, as well as collecting, transferring, storing and processing data.

In modern agriculture, there are several priority areas for technological development and innovation [7].

- tillage;

- farm machinery production;

- kettle breeding and keeping;

- soil irrigation and wetting;

- harvesting and storage;

- transportation and sale [8]

The digital economy in Russia is reported to rest on effective infrastructure that creates enabling conditions for the innovative development of production; ensures the operation of "smart" enterprises, environmental security, cyber protection of the virtual space and a corporate equilibrium of business; include communication hardware, computer networks, data processing centers and a system of virtual organizations; provide new digital services to the state, business and citizens in reliable communications, computing power, information systems, services, digital platforms through domestic technologies, as well as collecting, transferring, storing and processing data.

\section{Results and discussion}

After careful evaluation of automated processes in place at reclamation enterprises, there can be no doubt that, given a growing focus for the effectiveness of management decisions, it is necessary to improve the integration of digital systems and technologies [9]. Automation largely includes only scattered fragments of production activities, focusing mainly on accounting applications and some routine automation. Physical depreciation of reclamation water facilities and the dilapidated equipment hinder the implementation of innovative digital technologies for monitoring and accounting for operations at reclamation facilities.

Digital technologies used in the field of land reclamation are based on the software being replicated from overseas, which was developed for conditions other than domestic settings [10]. To readjust the borrowed software for automated production systems and adapt it to new production conditions, experts from the manufacturing and/or research companies are required to develop appropriate procedures, usually missing, which reduces the effectiveness of using the software, in some cases nullifying it.

The disadvantages that significantly limit the use of digital systems for management also include costly development, which requires managers to thoroughly evaluate and take a balanced decision regarding the size of investments in digital technologies and their management [11].

The main challenges associated with a low effect from the use of digital technologies by industrial entities are attributed to:

- the lack of a properly developed concept and methodology for the creation and subsequent implementation of digital systems at the enterprise, which does not contribute to the integrity of the information support system utilized;

- a low level of interaction between information resources and a digital management system, which reduce the effectiveness of management decisions;

- insufficient unification of digital corporate technologies for processing information, data storage standards and their inconsistency with world standards that restrain the integration of information resources at the corresponding hierarchical levels of corporate management [12];

- inconsistency of decision support system to modern management requirements, leading to a lower quality due to imbalance of production processes;

- a dearth of efficient human capacities motivated to improve the use of digital technologies.

In general, digital systems are created and implemented in the field of land reclamation through trial and error. There is an urgent need for a unified strategy aimed to develop digital technologies for the management of reclamation facilities, aligned with the strategy of informatization of business management level in the Russian Federation.

A fundamental requirement for effective digital technology to be implemented at an enterprise is the definition of goals and objectives pursued by automation, the composition and structure of a unit being automated in its relationship with the production units of the organization, which guarantees the success of the digital management structure, since "chaos cannot be automated" [13]. 
Table 1 shows a conceptual diagram of a digital enterprise management system.

Table 1. Conceptual diagram of a digital enterprise management system

\begin{tabular}{|c|c|c|}
\hline \multicolumn{3}{|c|}{ Organisation management } \\
\hline $\begin{array}{c}\text { Functional } \\
\text { subdivisions }\end{array}$ & $\begin{array}{c}\text { Technological } \\
\text { processes }\end{array}$ & Production units \\
\hline \multicolumn{3}{|c|}{ Enterprise digital management system } \\
\hline \multicolumn{3}{|c|}{ Decision support system } \\
\hline $\begin{array}{c}\text { enterprise } \\
\text { management } \\
\text { system }\end{array}$ & $\begin{array}{c}\text { technology } \\
\text { management } \\
\text { system }\end{array}$ & $\begin{array}{c}\text { production } \\
\text { management } \\
\text { system }\end{array}$ \\
\hline
\end{tabular}

A reliable integrated relationship between functional divisions creates necessary conditions enabling the development of a digital system.

The digital system of an enterprise should be implemented based on the principles of unification and standardization of the information used (in format and content) and digital technologies it comprises, which ensures the interconnection of both digital support of production processes and production agents.

Equally important is to think of a correct solution to the problem of interaction between software systems and digital technologies used for the effective impact of management decisions in specific production conditions, with the infrastructure for the development of a digital resource to provide the subsequent information support to production agents [14]:

- to fully automate both main and auxiliary processes;

- to integrate information processes;

- to provide electronic support of processes.

Consequently, digital enterprise management system should be structured by integrating access to information on technological processes and on items (services) being produced. The specified structure of digital systems implements the system and computer methods of regulating the competitiveness of an enterprise, ensuring the competitiveness of the created product throughout its entire life cycle, which is achieved by the efficiency of the interconnection of production processes within the enterprise, as well as between agents in the entire production chain [15].

Structuring and unification of information helps to reduce, almost completely eliminate, information "disorder" and communication barriers to regulate production and, as a result, to boost the effectiveness of digital operations related to the formation of production costs and properties of products.

The integration of the specified principle of creating digital systems provides effective control over production and increases the response from the digital management system to changes in technological processes. Operational decision-making procedures reduce the time required to create information necessary for management, and increase the validity of managerial actions, which promotes the organization in the business environment, thereby increasing the competitiveness of the manufacturer of products (services) [16].

The core of the structural diagram of corporate digital systems in the proposed setting is a database that serves as a source of information for all functional divisions and services of the organization. It includes information on products (services), material, technical, financial and labor resources, qualifications of employees, production technologies and equipment, etc., which provides all necessary support for managerial actions aimed at solving operational, tactical and strategic production tasks in accordance with targets set by the enterprise.

The digital decision support system exploited at the enterprise should evolve gradually with priority modalities to be shaped promising the maximum return on implementation, flexibly adjusting to the current features of production, economics, and policy in production, in the region and in the country.

The basic procedures for creating and/or improving corporate digital systems include:

- analytical evaluation of the existing production situation, product quality and competitiveness and the corresponding parameters of digital systems that offer a number of possibilities for solving future tasks;

- development of the fundamental structure of the integrated digital system of the enterprise;

- modelling of digital systems;

- establishment of a mechanism for the implementation of digital systems [17];

- implementation of a digital systems model;

- operation of the information and innovation system.

In the process of transforming digital support for management actions, the following decisions are possible [18]:

- restructuring of existing processes;

- automation of traditional technological and organizational production procedures;

- adjustment of current processes in accordance with the technologies being integrated;

- quest for new opportunities and new company infrastructure;

- improvement of certain production operations.

Search for promising factors of digitalization in agricultural production resulted in the priority evolution areas that include [19]:

- state-assisted establishment of a favorable environment for the development of digitalization of the farming industry [20];

- integration of IT innovations into a digital shell;

- development of appropriate equipment;

- availability of personnel with necessary professional expertise [21];

- promotion of subcontracting or outsourcing.

This transformation of digital decision support system contributes to the creation of corporate digital systems that integrates traditional specialized systems for production automation (computer-aided design), generative planning system, enterprise resource planning system, computer-aided manufacturing, etc. 
The block functional organization of digital systems, developed based on the above recommendations, provides the development of the database by attaching new data to existing ones without transforming the latter. Following the principle of permanent digital support for management decisions enhance the competitiveness of the organization through higher product quality and improved production costs [22].

\section{Conclusion}

The coming era of digitalization of production processes requires a traditional enterprise to transform and use modern production technologies in light of growing competition and struggle for survival, which is associated with the integration of production equipment into a single network and the establishment of a supportive innovation infrastructure.

The priority function of infrastructure is to solve common problems of innovative development, ensure access to resources, provide consulting and expert services, remove risks for participants in innovative activities. Enterprises gain access to additional space, assets and production and technological facilities, with a growing role of educational and research institutions as leading providers of innovations.

Digitalization involves establishing an infrastructure of digital spatial trust necessary to exchange data between people, business and the state.

A perspective direction of modern digitalization is the establishment of a "smart enterprise" that connects all systems on the basis of a single platform. This enterprise performs activities virtually "offline", freeing a human from routine actions and the costs incurred for manual control of processes.

The innovative development of the farming industry in Russia is slowing down due to the low level of technological equipment, the technological level of the industry and the insufficient level of staff qualifications. The general level of information processing by agricultural enterprises seems to be unsatisfactory for the following reasons:

- low performance of business entities in the process of creating a material and technical base, promoting digitalization and the influence of the state on the economic situation;

- lack of infrastructure to inform national agribusiness;

- lack of interest from companies - users of information systems and their products due to unsatisfactory incentives to produce the latter.

Special attention should be paid to the focus of the domestic industry and farming enterprises for the following areas of innovative development:

- modification of the existing infrastructure;

- application of product life cycle management (PLM) technologies;

- implementation of product data management (PDM) technologies;

- implementation of machine data collection (MDC) system;
- utilization of analytical decision support systems;

- adaptation of employees to innovations.

Thus, a theoretical and organizational basis for the creation of an innovative generalized digital system of land reclamation production, which ensures its competitiveness, is becoming one of the priority tasks set by the management of the land reclamation industry. The lack of proper concept and experience in solving this problem, its topicality and practical significance determined the topic and main recommendations of these studies.

\section{References}

1. H. Vater, E. Bail, Haufe-Lexware mbH\&Co. (2013)

2. P. Watson, N. Chileshe, D. Maslow, A Construction Industry Development 2nd Postgraduate Conference -Cape Town South Africa pp. 129-141 (2004)

3. I. V. Bogachev, Forum Cnews Transcript of the speech on November 14, 2013 Moscow (2013)

4. H. Hirsch-Kreinsen, Chelteham (UK, Edward Elgar Publishing Limited, 2014)

5. M. A. Bandurin, I. F. Yurchenko, I. P. Bandurina, International Multi-Conference on Industrial Engineering and Modern Technologies, Far East Conference 2019, 8933970 (2019)

6. M. Jeffrey, Data driven marketing. 15 indicators that everyone should know (Mann, Ivanov and Ferber, Moscow, 2013)

7. J. Carr, Publishing house Secret of the firm (2005)

8. D. A. Markov, Izvestiya of the Russian State Pedagogical University. A.I. Herzen, 12(90) (2009)

9. F. K. Abdrazakov, S. S. Orlova, T. A. Pankova, E. N. Mirkina, O. V. Mikheeva, Journal of Interdisciplinary Research, 8(1), 154-161 (2018)

10.S. Vladimirov, I. Prikhodko, T. Safronova, E. Chebanova, E3S Web of Conferences, 175, 12010 (2020)

11. L. V. Kireicheva, N. P. Karpenko, Eurasian soil science, 48(5), 524-532 (2015)

12. Report "Digital Russia: New Reality" (2017)

13. M. Porter, Competition (M: Ed. House "Williams", 2003)

14. V. I. Olgarenko, G. V. Olgarenko, I. V. Olgarenko, Melioration and water management, 6, 8-11 (2013)

15. V.I. Olgarenko, I.V. Olgarenko, V.I. Olgarenko, IOP Conference Series: Materials Science and Engineering, 698(2) (2019)

16. M. A. Bandurin, I. P. Bandurina, I. F. Yurchenko, Journal of Physics: Conference Series, 1728(1), 012001 (2021)

17. L. V. Kireicheva, O. A. Zakharova, Eurasian Soil Science, 35(9), 990-995 (2002)

18. M. A. Bandurin, V. A. Volosukhin, A. V. Mikheev, Y. V. Volosukhin, I. P. Bandurina International conference on 
mechanical engineering, automation and control systems 327 (2017)

19. T. Jaegers, Eurostat Statistics in focus (2013)

20. D. V. Kozlov, Water Resources, 28(2), 215-219 (2001)
21. R. Kumari et al., Journal of Regional Development and Planning, 3(2), 37-50 (2014)

22. E. Y. Adesta, T. D. Agusman, A. Avicenna, Indonesian Journal of Electrical Engineering and Informatics (IJEEI), 5(4), 376-382 (2017) 